\title{
Effect of Waste Bamboo Fiber Addition on Mechanical Properties of Soil
}

\author{
Motohei Kanayama ${ }^{*}$, Satoko Kawamura ${ }^{2}$ \\ ${ }^{1}$ Department of Food Production and Environmental Management, Faculty of Agriculture, Iwate University, Morioka, Japan \\ ${ }^{2}$ Naigai Engineering Co., Ltd., Tokyo, Japan \\ Email: *motohei@iwate-u.ac.jp
}

How to cite this paper: Kanayama, M. and Kawamura, S. (2019) Effect of Waste Bamboo Fiber Addition on Mechanical Properties of Soil. Open Journal of Civil Engineering, 9, 173-184.

https://doi.org/10.4236/ojce.2019.93012

Received: May 31, 2019

Accepted: July 2, 2019

Published: July 5, 2019

Copyright $\odot 2019$ by author(s) and Scientific Research Publishing Inc. This work is licensed under the Creative Commons Attribution International License (CC BY 4.0).

http://creativecommons.org/licenses/by/4.0/

(c) (i) Open Access

\begin{abstract}
For soil improvement, a method using plant fiber has been used since ancient times. In recent years, the construction method using plant fiber has attracted attention as a ground improvement technology with less environmental load. In this work, the soil improvement effect using waste bamboo fiber was experimentally examined. The liquid limit and plastic limit of the mixed soil tended to increase with increasing bamboo fiber content and there was no change in the plasticity index of the mixed soil by the difference of bamboo fiber content. As a result from the compaction test and unconfined compression test, it was revealed that mixing of bamboo fiber resulted in a reduction of soil material required for construction and increasing in strength. The maximum compressive stress of the bamboo fiber mixed soil at the mixing ratio of $0 \%, 1 \%, 3 \%$ and $5 \%$ were $115,108,130$ and $152 \mathrm{kN} / \mathrm{m}^{2}$, respectively. As the soil with fiber showed the lower stiffness and higher strength than that without fiber in the dry region, it can be judged that the addition of fiber brought ductility to the soil. And it was found that the decrease in the stiffness of the specimen due to the increase of water content was suppressed by the addition of the bamboo fiber. From the results of the observation with the digital microscope, it was observed that the two-layer structure consisting of the main relatively thick fibrous structure and the secondary capillary fibrous structure were formed. Thus, it was found that the complex structure of the bamboo fiber is deeply involved in the strength of the mixed soil.
\end{abstract}

\section{Keywords}

Industrial Waste, Bamboo Fiber, Andosol, Unconfined Compressive Strength, Soil Improvement

\section{Introduction}

In recent years, the invasion of neglected bamboo forest into Satoyama in Japan 
has become a more serious problem. When bamboo invades the surrounding fields and forests, the growth of other plants and trees will be inhibited as a result of light shielding by height and occupying the area by making groups. In addition, since the roots of bamboo spread widely in the ground as much as 30 $\mathrm{cm}$ depth, it is known that the watershed protection function declines, and landslides are induced if heavy rain falls. Bamboo grows fast and breeds by underground stems. Therefore, just removing the bamboo shoot does not mean that the bamboo itself is removed. Once bamboo invades Satoyama, it is difficult to completely remove them. For the above reasons, while maintaining the bamboo grove which has been excessively propagated, it is also required to establish the effective utilization method of bamboo and to bring the bamboo grove into profitability again.

In the improvement of ground during the construction of structures, the methods using plant fibers have been used for a long time. It is known that the stable improvement of soil material by not only bamboo waste materials but also natural substances has been done for thousands of years. Hejazi et al. [1] summarized the history of stable improvement of soil material by natural substances as follows. They stated that in the Mesopotamian civilization limestone was used as construction material with mixing into weak soil, and in various ancient civilizations straw and hay, etc. were mixed with mud and those were used as a sun-dried brick. They also stated that people were improving the ground soil using familiar plant fibers in the Great Wall of China and Ziggurat of Babylon respectively. Furthermore, the ground improvement by natural fibers such as hemp, jute, coconut and bamboo has been done for more than 5000 years as a traditional construction method.

Various improvements of building materials using the bamboo have been carried out by efforts to eliminate the bamboo groves problem and development of construction method considering the environment in recent years. Several studies showed that the bamboo fiber was the suitable fiber for mixing with the cement material [2] [3]. It is clarified that the improvement effect was much superior to that by other fibers. As a further improvement, various fibers are added into lime-soil to enhance the mechanical properties, and to reduce the vertical and lateral deformation [4] [5] [6]. Nishida et al. [7] investigated the improvement effect due to the high water absorption by adding the bamboo waste material with the cementitious solidifying material to the bottom sediment with high water content. As a result, it was clarified that the bottom sediment with high water content can be improved to the transportable strength by adding the bamboo waste material. It was also revealed that the improvement effect was larger for the water absorbing material with higher water absorption ratio. Yamashita et al. [8] studied the strength and cracking characteristics of the building wall mixed with the bamboo as the reinforcing material. As a result, it was revealed that the unconfined compressive strength of the wall clay mixed with the 
bamboo was greater than that of the conventional wall clay mixed with the straw. In addition, it was revealed that the cracked area ratio decreased by increasing the added amount of the reinforcing material regardless of that type. In particular, it was reported that the effect of suppressing cracks was remarkable in the bamboo fiber with long fiber length. Sako et al. [9] examined the availability of the bamboo chips to prevent the erosion of the promenade in the historic site. As a result, it was revealed that the specimens mixed with the bamboo chips had high erosion resistance and increased the unconfined compression strength. Otsubo et al. [10] used the bamboo fiber as the base material for the sprayer in the greening plant of the slope, and investigated the erosion preventing the effect of the base material itself. They showed that utilizing the bamboo fiber resulted in less erosion than the conventional methods. Sato et al. [11] have extensively investigated the improvement of soft clay by incorporating bamboo chips and flakes that have high water absorption characteristic of bamboo material. Brahmachary and Rokonuzzaman [12] conducted the number of soaked and unsoaked CBR value tests for ordinary soil and soil mixed with different quantity of bamboo fiber, and concluded that both unsoaked and soaked California Bearing Ratio (CBR) value of soil increases due to the addition of bamboo fiber. Devi and Jempen [13] investigated the shear strength behavior of a bamboo fiber reinforced soil. They showed an increase in the shear strength parameters of the soil with an increase in the percentage of fiber up to an optimum amount. Ismanti and Yasufuku [14] presented the utilization of natural and environmental-friendly material, bamboo chips, mixed with a small amount of cement content in soil improvement. Thus, fiber-soil has been attracting attention in geotechnical engineering [15] [16].

As described above, various studies on soil improvement using bamboo waste materials have been conducted all over the world. From the results of the past research, it can be judged that the ground improvement by the bamboo waste material can be applied to the embankment work at general civil engineering sites and the levee embankment at the agricultural field. Generally, relatively rough bamboo chips and flakes are the common fiber conditions used in those research, and the research as for the application of fine bamboo powder is not much. In this paper, focusing on the relatively fine bamboo powder, the physical and mechanical characteristics of the bamboo fiber mixed soil were experimentally investigated and the effect of the improvement was clarified.

\section{Material and Methods}

In this experiment, the andosol collected from the field in Iwate University was used as soil material. The bamboo fiber, which was fibro used after logging and commercially available, was used. This bamboo fiber contains fibers of various sizes. When $1 \mathrm{~kg}$ bamboo fibers were classified using sieves of 2, 0.85 and 0.425 $\mathrm{mm}$, the residual fractions of $2,0.85$ and $0.425 \mathrm{~mm}$ were $13 \%, 16 \%$ and $21 \%$, re- 
spectively, and the fraction passing through $0.425 \mathrm{~mm}$ was $50 \%$. This indicates that this bamboo fiber contained many fine powdery particles. In order to investigate the effect of improving by addition of bamboo fiber and the influence of compounding ratio on improving effect, the experiments conducted in this study were 1) water absorption test of bamboo fiber, 2) liquid limit test and plastic limit test, 3) compaction test, 4) unconfined compression test, 5) image observation of specimens by digital microscope. The physical properties of the soil are shown in Table 1.

\subsection{Water Absorption Test of Bamboo Fiber}

In order to evaluate the effect of moisture content and water absorption time of the bamboo fiber on water absorption rate, the water absorption test of the bamboo fiber was carried out. The specimens with the moisture content of $10 \%$ dried by natural air and $0 \%$ absolutely dried by the oven were used. The bamboo fiber corresponding to $1 \mathrm{~g}$ of dry mass was added to the beaker filled with distilled water and stirred, and then absorbed for 1 or 1440 minutes. After water absorption, the water absorbing sample was poured into the funnel and it was confirmed that the surplus water was sufficiently dropped, and then the mass of the bamboo fiber was measured. In this study, the water absorption rate was defined as the ratio of the mass of absorbed water to the dry mass of the bamboo fiber as following.

$$
A_{r}=m_{w} / m_{b} \times 100
$$

where $A_{r}$ is the water absorption rate, $m_{w}$ is the mass of absorbed water in the bamboo fiber, $m_{b}$ is the dry mass of the bamboo fiber.

\subsection{Liquid Limit Test and Plastic Limit Test of Bamboo Fiber Mixed Soils}

In order to evaluate the influence of difference in the bamboo fiber content on the consistency of the bamboo fiber mixed soil, the liquid limit test and the plastic limit test was conducted. The mass mixing ratio of the bamboo fiber to the dry soil mass was $0 \%, 1 \%, 3 \%$ and $5 \%$. Both tests were carried out in conformity with Japanese Industrial Standard JIS A 1205.

\subsection{Compaction Test of Bamboo Fiber Mixed Soils}

In order to evaluate the effect of difference in bamboo fiber content on the

Table 1. Physical properties of soil.

\begin{tabular}{cc}
\hline Soil particle density $\rho_{\mathrm{s}}\left(\mathrm{g} / \mathrm{cm}^{3}\right)$ & 2.727 \\
Sand content $(\%)$ & 28 \\
Silt content $(\%)$ & 44 \\
Clay content $(\%)$ & 28 \\
Fine particle content $\mathrm{F}_{\mathrm{c}}(\%)$ & 72
\end{tabular}


maximum dry density and the optimum water content of the bamboo fiber mixed soil, the compaction test by tamping with bamboo fiber mixed soil was carried out. The mass mixing ratio of the bamboo fiber to the dry soil mass was $0 \%, 1 \%, 3 \%$ and $5 \%$. Table 2 shows the condition of the compaction test. The test was carried out in conformity with Japanese Industrial Standard JIS A 1210.

\subsection{Unconfined Compression Test of Bamboo Fiber Mixed Soils and Image Observation}

In order to evaluate the unconfined compressive strength as an index when handling as a ground improvement material on site, the unconfined compression test of the specimen prepared by the compaction test was carried out. The test was conducted in conformity with Japanese Industrial Standard JIS A 1216 by using the universal compression tester (RTG-1210 manufactured by A\&D Co., Figure 1). The compression rate was set to compressive strain $1 \% / \mathrm{min}$.

The influence on unconfined compressive strength of the mixed soil was examined by changing the mass mixing ratio of the bamboo fiber to the dry soil mass to $0 \%, 1 \%, 3 \%$ and $5 \%$, respectively. Furthermore, a part of the specimen after the unconfined compression test was sampled and the change of the structural skeleton due to the addition of the bamboo fiber was observed by using the digital microscope (UM 06 manufactured by Kenis Co., Figure 1).

\section{Results and Discussion}

\subsection{Results of Water Absorption Test of Bamboo Fiber}

The results of the water absorption test are shown in Table 3. The bamboo fiber used in this study was found to have a very high water absorption rate of $742.8 \%$ $775.4 \%$. Focusing on the water absorption time of the bamboo fiber in this test result, there was no difference in the water absorption rate between the water

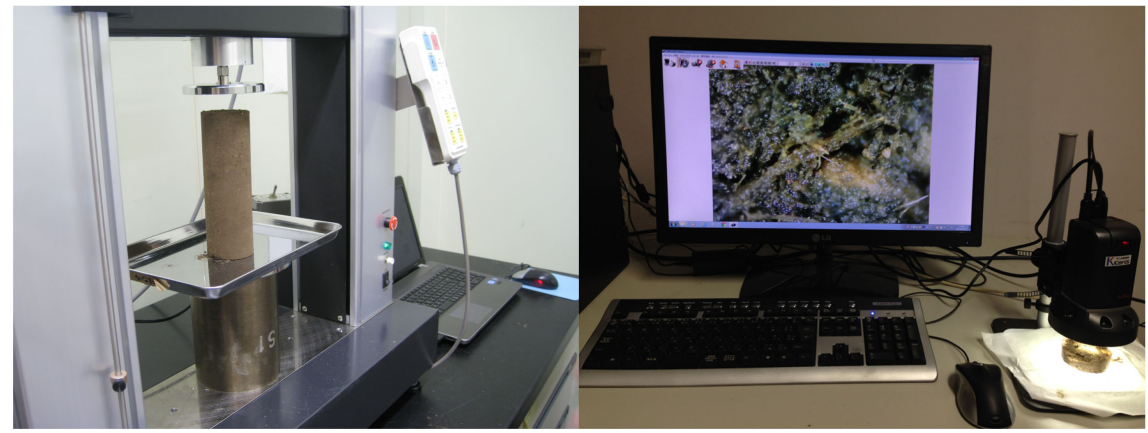

Figure 1. Universal compression tester and digital microscope.

Table 2. Condition of compaction test.

\begin{tabular}{cccccc}
\hline $\begin{array}{c}\text { Rammer Mass } \\
(\mathrm{kg})\end{array}$ & $\begin{array}{c}\text { Falling Height } \\
(\mathrm{cm})\end{array}$ & $\begin{array}{c}\text { Mold Inner } \\
\text { Diameter }(\mathrm{cm})\end{array}$ & $\begin{array}{c}\text { Mold Volume } \\
\left(\mathrm{cm}^{3}\right)\end{array}$ & $\begin{array}{c}\text { Number } \\
\text { of Layers }\end{array}$ & $\begin{array}{c}\text { Number of } \\
\text { tamps per layer }\end{array}$ \\
\hline 1.25 & 30 & 6 & 550 & 3 & 25 \\
\hline
\end{tabular}


Table 3. Results of water absorption test of bamboo fiber.

\begin{tabular}{ccc}
\hline $\begin{array}{c}\text { Initial Water Content } \\
\text { in Bamboo Fiber (\%) }\end{array}$ & Absorption Time (min) & Water Absorption Rate $A_{r}(\%)$ \\
\hline 0 & 1 & 775.4 \\
& 1440 & 772.3 \\
10 & 1 & 751.5 \\
& 1440 & 742.8 \\
\hline
\end{tabular}

absorption time 1 minute and 1440 minutes at either water content ratio. On the other hand, in terms of the initial water content ratio, the water absorption rate of the bamboo fiber with $0 \%$ initial water content was higher by about $30 \%$ than that with $10 \%$ initial water content. This is thought to be the thermal denaturation due to the oven-drying of the bamboo fiber, so it is presumed that the water absorption rate of the bamboo fiber has increased.

Nishida et al. [7] reported that the water absorption rate varies depending on the condition of the bamboo fiber, based on the water absorption test results. They showed that as the bamboo fiber became coarser the water absorption rate became lower, and the lowest value was $102.5 \%$. On the contrary, they also reported that the cotton-like bamboo fiber has a higher water absorption rate, and the highest value was $455.1 \%$. Hejazi et al. [1] summarize that the water absorption rate of bamboo before fiberization is about $40 \%$ to $45 \%$. Based on the results of the past research and the sieve analysis of bamboo fiber, it can be judged that the high water absorbency in this study is caused by the amount of finer bamboo fiber. According to this result, it is revealed that the improvement effect such as the bottom sediment with high water content is larger for the finer bamboo fiber.

\subsection{Results of Liquid Limit Test and Plastic Limit Test of Bamboo Fiber Mixed Soils}

In the liquid limit test and the plastic limit test, both limits tended to increase with increasing bamboo fiber content as shown in Table 4. It is noted that the plasticity index is the difference between the liquid limit and the plastic limit and the flow index is the gradient of the flow curve in the liquid limit test, defined as following equations.

$$
\begin{gathered}
I_{p}=w_{L}-w_{p} \\
I_{f}=\left(w_{1}-w_{2}\right) /\left(\log N_{2}-\log N_{1}\right)
\end{gathered}
$$

where $I_{p}$ is the plasticity index, $w_{L}$ is the liquid limit, $w_{p}$ is the plastic limit, $I_{f}$ is the flow index, and $W$ and $N$ indicate arbitrary water content and number of drops in the liquid limit test, respectively.

The liquid limit increased $47.7 \%, 46.8 \%, 48.3 \%$ and $51.8 \%$ and the plastic limit increased $34.6 \%, 34.4 \%, 36.3 \%$ and $38.5 \%$ at the bamboo fiber content $0 \%, 1 \%$, $3 \%$ and $5 \%$, respectively. These increases are caused by the high water absorption of bamboo fiber. Both tests with $10 \%$ bamboo fiber content were also 
Table 4. Results of liquid limit and plastic limit of the mixed soil.

\begin{tabular}{ccccc}
\hline $\begin{array}{c}\text { Fiber Content } \\
(\%)\end{array}$ & $\begin{array}{c}\text { Liquid Limit } \\
w_{L}(\%)\end{array}$ & $\begin{array}{c}\text { Plastic Limit } \\
w_{p}(\%)\end{array}$ & $\begin{array}{c}\text { Plasticity Index } \\
I_{p}\end{array}$ & $\begin{array}{c}\text { Flow Index } \\
I_{f}\end{array}$ \\
\hline 0 & 47.7 & 34.6 & 13.1 & 3.5 \\
1 & 46.8 & 34.4 & 12.4 & 5.3 \\
3 & 48.3 & 36.3 & 12.0 & 6.8 \\
5 & 51.8 & 38.5 & 13.3 & 7.4 \\
\hline
\end{tabular}

conducted. However, since the properties of bamboo fiber became dominant and the consistency of the soil was lost, both limit values could not be detected. The plasticity index showed an almost constant value of about 12 to 13 regardless of the bamboo fiber content in this test. This is due to the increments of both limit values with the increase of the bamboo fiber content. As a result it was found that there was no change in the plasticity index of the mixed soil by the difference of the fiber content. The flow index, which is equivalent to the gradient of the flow curve in the liquid limit test, increased with an increase of the fiber content. This means that the fiber mixed soils become difficult to flow as the mixing ratio increases.

\subsection{Results of Compaction Test of Bamboo Fiber Mixed Soils}

The results of the compaction test for the bamboo fiber mixed soils are shown in Figure 2. It can be seen that the higher the bamboo fiber content, the lower compaction curve tends to be located. At bamboo fiber content $0 \%, 1 \%, 3 \%$ and $5 \%$, each maximum dry density was $1.19,1.17,1.14$ and $1.07 \mathrm{~g} / \mathrm{cm}^{3}$, respectively, similarly each optimum water contents was $32.3 \%, 34.9 \%, 35.5 \%$ and $36.8 \%$, respectively. Thus, it was found that as the bamboo content increased, the maximum dry density decreased and the optimum water content increased. According to this result, the unit volume weight of bamboo fiber mixed soil at the maximum dry density becomes smaller, which means that the mixed soil becomes very lightweight as a material.

Using this result, the calculation was done about the mass of each bamboo fiber mixed soil necessary for compacting $1 \mathrm{~m}^{2}$ with $30 \mathrm{~cm}$ in thickness at the optimum water content. For the sample soils with the bamboo fiber mixing content $0 \%, 1 \%, 3 \%$ and $5 \%$, the mass required for the construction can be estimated to be $356.2,351.8,342.0$ and $320.4 \mathrm{~kg}$, respectively. Comparing the required mass of $0 \%$ and $5 \%$ mixed soil, $5 \%$ mixed soil is about $35 \mathrm{~kg}$ lighter. Assuming an actual construction site, it is considered that the weight loss of this soil sample is economically beneficial.

\subsection{Results of Unconfined Compression Test of Bamboo Fiber Mixed Soils and Image Observation}

The stress-strain curves of the mixed soils derived from unconfined compression test are shown in Figure 3. It is found that the compressive stresses of all 


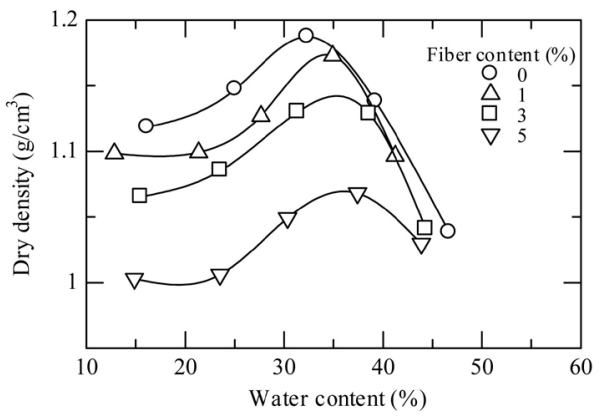

Figure 2. Results of the compaction test for the bamboo fiber mixed soils.
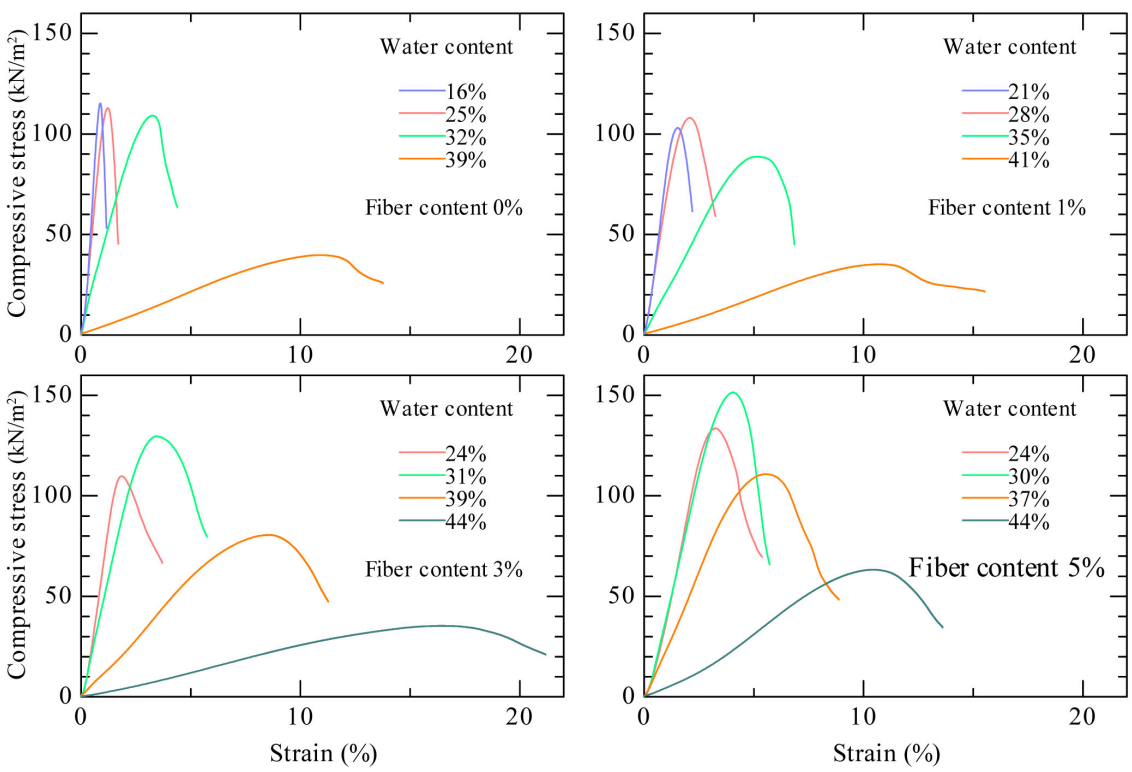

Figure 3. Stress-strain curves of mixed soils derived from unconfined compression test.

specimens tended to increase with an increase in the bamboo fiber content. The maximum compressive stress of the bamboo fiber content $0 \%, 1 \%, 3 \%$ and $5 \%$ were $115,108,130$ and $152 \mathrm{kN} / \mathrm{m}^{2}$.

There was no difference in the stress-strain curves between the bamboo fiber content $0 \%$ and $1 \%$. According to this result, the bamboo fiber mixing content was less than $1 \%$, it was found that there was no improvement in the mechanical properties of the soil due to the mixing of the bamboo fiber. When the bamboo fiber content is above $3 \%$, it is found that the maximum compressive strength is exhibited at the optimum water content. Furthermore, the slope of the initial linear part in the stress-strain curve at high water content are tended to be steep when the bamboo fiber content increased.

Figure 4 shows the relationship between deformation modulus and water content of mixed soils with different fiber content. It is interesting that the tendency of the stiffness characteristics of the specimens differs depending on the presence and content of fibers. The soil with no fiber showed the high deformation modulus at the dry region and then decreased steeply with an increase of 


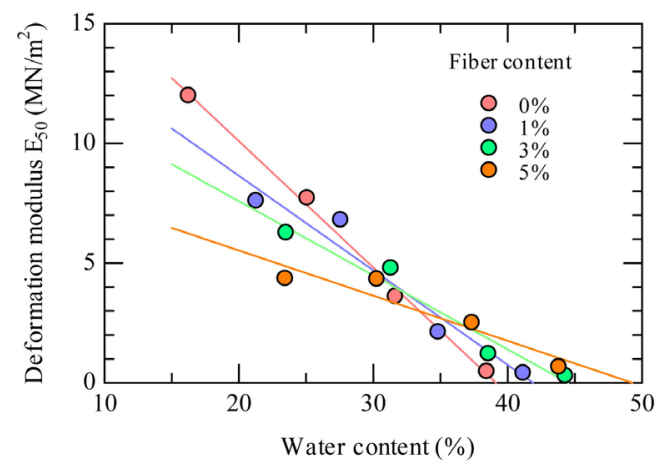

Figure 4. Effect of bamboo fiber addition on deformation modulus of mixed soils.

the water content. On the other hand, the soil with fiber showed the lower deformation modulus and decreased gradually. Considering the lower stiffness and higher strength of the soil with the fiber than those without fiber in the dry region, it can be judged that the addition of fiber brought ductility to the soil. And it is obvious that as the addition of fiber increased, the rate of decrease in the deformation modulus became slower. Finally, it can be seen that in the wet region the deformation modulus with or without fiber was reversed. This means that the decrease in the stiffness of the specimen due to the increase of water content was suppressed by the addition of the bamboo fiber, the cause is considered to be due to the absorbency and structure of the bamboo fiber.

Figure 5 shows the relationship between the maximum dry density and the unconfined compressive strength when bamboo fiber content is changed. It was found that the strength of mixed soil increases and the maximum dry density decreases due to the increase of bamboo fiber content. From this result, it was clarified that the mixing of the bamboo fiber to the soil contributes to the increase of the strength of the soil. It is expected to be utilized the bamboo mixed soil as a lightweight civil engineering and agricultural material, such as ground base reinforcement.

Figure 6 shows the result of image observation with the digital microscope.

It was confirmed that the bamboo fiber was placed very irregularly with respect to the inside soil and so as to embrace the soil particles. Focusing on the bamboo fibers, the structure was such that the thin fibers branch off from the main fibers. In this way, it was observed that the two-layer structure consisting of the main relatively thick fibrous structure and the secondary capillary fibrous structure was formed. Figure 6 also shows the schematic diagram for this structure. As these bamboo fibers have high water absorbency, it could be imagined that the fiber has remarkable water retention function, especially in the capillary fibrous structure. Moreover, it is considered that the soil particles are bonded by the capillary fiber and their aggregations induce frictional forces on the fibers with interlocking forces. These complex forces are a relation to mobilize the tensile stress on the fiber itself, it is suggested that the two-layer structure contributes to the increase in strength of specimens. 


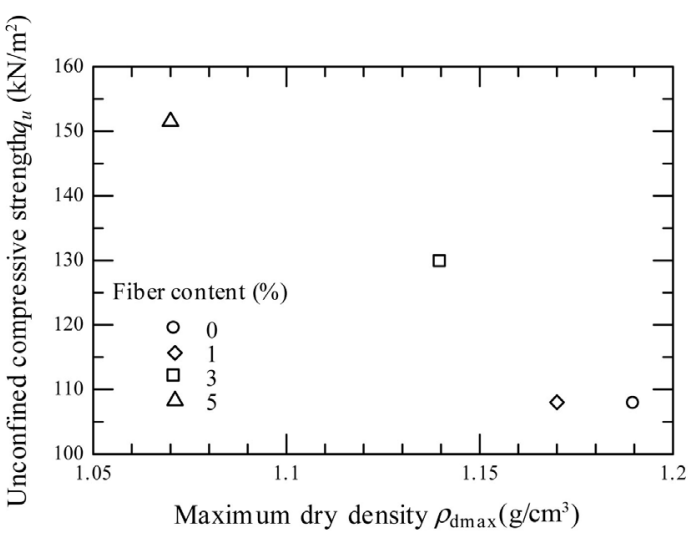

Figure 5. Relationship between maximum dry density and unconfined compressive strength.

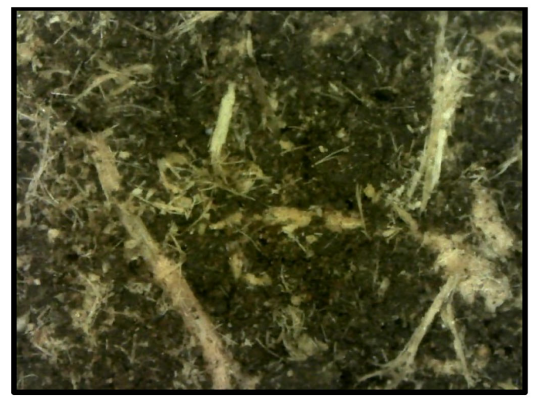

Fiber content $5 \%$

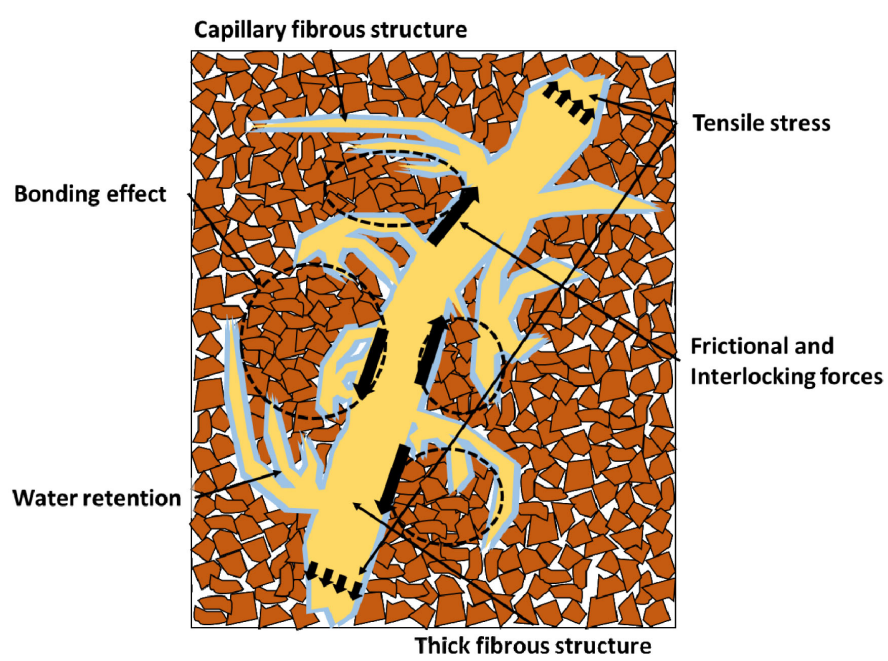

Figure 6. Picture of inside specimen with water content $32 \%$ and schematic diagram for two-layer structure.

\section{Conclusions}

The purpose of this research is to propose an effective utilization method of waste bamboo material. In this paper, the physical and mechanical characteristics of the bamboo fiber mixed soil were investigated and the effect of the improvement was clarified. The main results obtained are as follows. 
1) The bamboo fiber used in this study contained many fine powdery particles and was found to have a very high water absorption rate of $742.8 \%-775.4 \%$.

2) The liquid limit and plastic limit of the mixed soil tended to increase with increasing bamboo fiber content and there was no change in the plasticity index of the mixed soil by the difference of bamboo fiber content.

3) From the result of the compaction test, it was found that the maximum dry density of the mixed soil decreased and the optimum water content of the mixed soils increased with an increase of the bamboo fiber content. According to this result, the unit volume weight of the bamboo fiber mixed soil at the maximum dry density becomes smaller, which means that it becomes very lightweight as a construction material.

4) From the unconfined compression test, it was found that the compressive stresses of all specimens tended to increase with an increase in the bamboo fiber content. The maximum compressive stress of the bamboo fiber content $0 \%, 1 \%$, $3 \%$ and $5 \%$ were $115,108,130$ and $152 \mathrm{kN} / \mathrm{m}^{2}$. The soil with fiber showed the lower stiffness and higher strength than that without fiber in the dry region, it can be judged that the addition of fiber brought ductility to the soil. And it was found that the decrease in the stiffness of the specimen due to the increase of water content was suppressed by the addition of the bamboo fiber.

5) From the results of observation with the digital microscope, it was found that the complex structure of the bamboo fiber is deeply involved in the strength of the sample.

The bamboo fibers used in this study contained the fibers of various shapes. In the next step, it is necessary to study the influence of their shape and the amount of addition on the mechanical properties of the mixed soil.

\section{Acknowledgements}

Financial supports for this study have been provided partially by the Ministry of Education, Culture, Sports, Science and Technology, Japan (Grant in Aid for Scientific Research, No. 18K05875). The authors would like to express the deepest gratitude.

\section{Conflicts of Interest}

The authors declare no conflicts of interest regarding the publication of this paper.

\section{References}

[1] Hejazi, S.M., Sheikhzadeh, M., Abtahi, S.M. and Zadhoush, A. (2012) A Simple Review of Soil Reinforcement by Using Natural and Synthetic Fibers. Construction and Building Materials, 30, 100-116. https://doi.org/10.1016/j.conbuildmat.2011.11.045

[2] Ramaswamy, S., Ahuja, M. and Krishnamoorthy, S. (1983) Behavior of Concrete Reinforced with Jute, Coir, and Bamboo Fibers. International Journal of Cement 
Composites and Lightweight Concrete, 5, 3-13.

https://doi.org/10.1016/0262-5075(83)90044-1

[3] Coutts, P. and Ni, Y. (1995) Autoclaved Bamboo Pulp Fiber Reinforced Cement. Cement and Concrete Composites, 17, 99-106.

https://doi.org/10.1016/0958-9465(94)00002-G

[4] Kalkan, E. (2013) Preparation of Scrap Tire Rubber Fiber-Silica Fume Mixtures for Modification of Clayey Soils. Applied Clay Science, 80-81, 117-125. https://doi.org/10.1016/j.clay.2013.06.014

[5] Anggraini, V., Asadi, A., Huat, B.B.K. and Nahazanan, H. (2015) Effect of Coir Fibers on Tensile and Compressive Strength of Lime Treated Soft Soil. Measurement, 59, 372-381. https://doi.org/10.1016/j.measurement.2014.09.059

[6] Ayeldeen, M. and Kitazume, M. (2017) Using Fiber and Liquid Polymer to Improve the Behaviour of Cement Stabilized Soft Clay. Geotextiles and Geomembranes, 45, 592-602. https://doi.org/10.1016/j.geotexmem.2017.05.005

[7] Nishida, M., Sato, K. and Fujikawa, T. (2011) Water Absorption Effect of Bamboo Flakes Contributing to Improvement of High Water Content Sediment. Proceedings of the JSCE Annual Meeting, 66, 545-546.

[8] Yamashita, R., Yamanaka, M., Kotake, N., Utsunomiya, N. and Miyamoto, M. (2013) Strength and Shrink Age Crack Properties of Wall Clay Reinforced by Bamboo Fiber. Geosynthetics Engineering Journal, 28, 149-154.

[9] Sako, K., Kitamura, R., Kawaji, T. and Yotsuda, T. (2013) Erosion Resistant Properties of Improved Soil Using Bamboo Chipsfor Erosion Prevention of Alameda in Historic Places. Journal of Disaster Mitigation for Urban Cultural Heritage, 7, 39-44.

[10] Otsubo, M., Sugimoto, A., Furuno, K., Tsuji, H. and Higashi, T. (2014) Resistance to Erosion of Bamboo Fiber as a Slope Greening Substrate. Science Bulletin of the Faculty of Agriculture, Kyushu University, 69, 47-54.

[11] Sato, K., Fujikawa, T. and Koga, C. (2014) Improved Effect of the High Water Content Clay Using the Water Absorptivity of Bamboo. Geosynthetics Engineering Journal, 29, 191-196.

[12] Brahmachary, T.K. and Rokonuzzaman, M. (2018) Investigation of Random Inclusion of Bamboo Fiber on Ordinary Soil and Its Effect CBR Value. International Journal of Geo-Engineering, 9, 10. https://doi.org/10.1186/s40703-018-0079-x

[13] Dipika Devi, D. and Jempen, B. (2016) Shear Strength Behaviour of Bamboo Fiber Reinforced Soil. International Research Journal of Engineering and Technology, 3, 433-437.

[14] Ismanti, S. and Yasufuku, N. (2016) Effect of Bamboo Chips in Cemented Sand Soil on Permeability and Mechanical Properties in Triaxial Compression. International Journal of Geological and Environmental Engineering, 10, 917-923.

[15] Fagone, M., Loccarini, F. and Ranocchiai, G. (2017) Strength Evaluation of Jute Fabric for the Reinforcement of Rammed Earth Structures. Composites Part B: Engineering, 113, 1-13. https://doi.org/10.1016/j.compositesb.2016.12.054

[16] Ghosha, S.K., Bhattacharyyab, R. and Mondal, M.M. (2017) Potential Applications of Open Weave Jute Geotextile (Soil Saver) in Meeting Geotechnical Difficulties. Procedia Engineering, 200, 200-205. https://doi.org/10.1016/j.proeng.2017.07.029. 